\title{
The Cloud-to-Ground Lightning Parameterization Development with the Canadian Local
}

\section{Climate Model}

Abderrazak Arif

National Institute of Meteorology, B.P. 156, 2035 Tunis-Carthage, Tunis, Tunisia. abderrazak.arif@meteo.tn, Abderrazak.001@gmail.com (Corresponding author)

Tel: +21624543355

Fax: +21671772609

\begin{abstract}
We use the third version of the Canadian Local Climate Model as a diagnostic tool to study the climatology of observed CG lightning activity at Maniwaki (latitude: $46,23^{\circ} \mathrm{N}$; Longitude: $\left.75,58^{\circ} \mathrm{W}\right)$. We examine the dependence between the hourly lightning activity and the related atmospheric variables during the warm season of sixteen years (between 1988 and 2004). The goal of this research is: a) to evaluate the atmospheric static state evolution and its moisture contents for conditions having generated lightning occurrence, b) to develop a CG lightning parameterization, and c) to verify this CG lightning parameterization on other Canadian areas. The freezing level altitude and the precipitable water content are used to estimate the static air instability and its moisture content respectively. These two parameters are served to develop the CG lightning parameterization. A comparison between the observations and simulations CG lightning occurrence and frequency at Maniwaki showed a mean absolute error rate of $27 \%$ and $55 \%$ respectively. We apply this parameterization at four Canadian regions, distributed from west to east. The simulated CG lightning results are comparable to observed CG lightning at Maniwaki and tested regions. The application of the CG lightning parameterization to the daily data enabled us to find the monthly results. This application represents a preliminary stage for validation this parameterization in regional numerical models in Canada during the historic period.
\end{abstract}

Keywords: Parameterization, climate, Lightning, Atmosphere, Modelling, Thunderstorm, Convection, Forest, fires. 


\section{Introduction}

In Canada, the boreal forest is threatened by both natural and anthropogenic disturbances. Natural disturbances are dominated by: insects, forest fires and air pollution, for example acid rains $[62,23,33,38]$. The vast majority of forest fires are caused by lightning [41,6]. Human forest fires causes presents an anthropogenic threats in the boreal regions. Thus, forest fires remain the most important threat in term of area size and volume. However, fires forests devastate the maximum of the forest surface and affect the Canadian economy. The forest fires affect also the climate and are responsible for a significant quantity of greenhouse gases.

According to statistics obtained between 1988 and 1998 [13], 8823 fires devastated 3.2 million hectares, or $0.73 \%$ of the Canadian forest territory per year. Lightning causes $42 \%$ of all forest fires and accounts for $85 \%$ of the annually burnt surfaces destroying an average of 2.8 million hectares of forests. Human action burns only $15 \%$ of the total surfaces cause $58 \%$ of all fires. Anthropogenic threats are industrial harvesting [73], pollution [20,38], man-made forest fire [22], and climate changes $[4,72,5,46]$.

In the boreal region, forest fires remain the most important threat in term of area size and volume. Forest fire dynamics is very complex since it combines synergistically the natural and anthropogenic disturbances. Lightning frequency causing forest fires modify the climate through the changes of carbon concentration and other greenhouse gases in the atmosphere $[64,14]$, hydrologic alterations [21] or aerosols emissions by the smoke emission during forest fires $[66,60,61]$. From these facts, it becomes important to study the behavior of lightning using systemic approaches. Numerical modeling provides us an appropriate theoretical framework to evaluate the lightning frequency dynamics in a context of climate changes. 
The study of lightning and its distribution at regional and global scale under climate change relevant to many fields as forestry, security and atmospheric sciences $[69,27,7,28,25,36,50,59,78,58]$. There have been several studies correlating annual lightning density (impacts $\mathrm{km}^{-2}$ year ${ }^{-1}$ ) to number of days with lightning. In one of these studies appear them of Mackerras [29], Anderson and Erikson [1], and Soriano et al. [50] concerning Australia, South Africa and Spain respectively.

Other studies are correlated the lightning frequency with the atmospheric parameters. In one of these studies, Williams [76] showed the proportionality between the electric intensity and the fifth power of the cloudy column height. He developed an empirical equation between the total lightning frequency and the convective cloud height, on basis of the theoretical electric equations, lightning occurrence and standard aerological data.

Price and Rind [68] used the Williams's lightning parameterization applicable in continental regions, to develop a lightning parameterization in maritime regions. They use this lightning parameterization with the global climate model (GCM/GISS) from Goddard Institute for Space Studies to calculate the total lightning frequency (intra-cloud and cloud-ground) at global scale.

Granström [17] showed in a study carried out in Sweden that lightning frequency is related to precipitation during the summer season. Other researchers found a strong correlation between lightning frequency and physical parameters of storm systems. Williams and Renno [77] found a correlation between lightning occurrence and Convective Available Potential Energy (CAPE) at occidental pacific tropical regions with $300 \mathrm{~km}$ radius around during January 1993 to February 1994.

Hauf [24] showed a decrease in lightning frequency from the Southwest to the Northeast in Southern part of Germany during 5 years (1992-1996) where the spatial and temporal lightning distribution mean are dominated by simple thunderstorms. A study elaborated by Wierzchowski 
et al. [74], examine the combustible, the climate and the topography influences with forest fires caused by lightning at British-Colombia and Alberta, showed a significant difference of lightning frequency and forest fires caused by lightning at East and West of these regions.

Soriano et al. [49] analyzed the relationship between flash density and the number of thunderstorm days. They used a statistical method between cloud-to-ground flash densities, dew-point temperature at $850 \mathrm{hPa}$ and temperature difference between $850 \mathrm{hPa}$ and $700 \mathrm{hPa}$ to estimate the lightning capacity and density. Also, Zhou et al. [79] found a correlation between precipitation and the CG lightning frequency. This study is related to 16 stations in China for July 27 and 30, 1997 and for the precipitation period between 14:00h and 20:00h.

Other lightning studies aimed at the investigation of electrical phenomena and atmospheric conditions associated to lightning generation [35,47,48,67]. For example, Solomon et al. [49] studies the microphysics and electric proprieties linked to convective cells during three days (3-5 August 2002) at North of Italy, using a thunderstorm model of Washington University (UWTM, University of Washington $1.5 \mathrm{dim}$ thunderstorm model).

They found a strong correlation between the microphysics proprieties and cloud dynamics. Their preliminary results shown that the electric charges quantity, produced during this experience, depends to temperature, liquid water quantity and their particle sizes. They mentioned that the CG lightning do not formed necessary in depth convection or thunderstorm. The presence of an important ice crystals concentration in the convective clouds is a necessary condition to the presence of the lightning where they showed proportionality between them.

Presently, they have not a regional CG lightning parameterization developed with climatic parameters. In this study, we will focus on the climatic parameters to analyze and evaluate the lightning occurrence and frequency adapted to regional and global climate models and in particular, with the Canadian RCM [9]. We will concentrate over a long period of observations 
at the Maniwaki station near Ottawa and Montreal, in Canada. We will examine with precision the aerological data in relation with corresponding lightning occurrence and frequency during the warm seasons of 1988 to 2004 . However, since lightning occurrences for 1991 are missing, this year is not included in our study. The CG lightning frequency indicates here the instantaneous number of the lightning for one hour, one day or one month. The CG lightning occurrence represents the number of hours for one day or one month whatever its frequency. We demonstrate the robustness of this relationship and we will need to verify our parameterization in Canada using four regions. Our result is limited to CG lightning type since it presents the natural causes to forest fire ignition.

\section{Method}

As mentioned bellow, several studies showed a relationship between CG lightning frequency and the geographical location, orographic and climatic parameters $[24,53,50,79]$. This lightning regional dependence of parameterization prediction is not based on basic physical principles but on global statistics of thermodynamic variables responsible to the depth convection development. In physical climatology, atmospheric variables are more basic element for the lightning occurrence. The use of a physical approach with the statistic means remains an effective method to the CG lightning parameterization development.

The combination of several effects like the topography $[55,56,50]$ and the presence of the urban zone [56] reinforce the storm development could produce the CG lightning occurrence. The regional conditions cannot be excluded as for their impacts on the thunderstorm formation, but the atmospheric and climatic prognostic variables (temperature, moisture, pressure and wind) are most fundamental and the most robust predictors to determine the convective and violent atmospheric probabilities. Also, these variables define the necessary conditions for the CG 
lightning occurrence. Mainly, we could combine all relevant parameters but in detriment of the analysis and the complexity increase risks, of interpretation and to introduce a certain redundancy since the other predictive are taken from the model variables. For this study, we identified and selected two climatic variables linked to the CG lightning occurrence: the temperature and the moisture content. Insofar where all other model variables rise from these fundamental variables, they are implicitly associated. Also, the constraints effect like topography and the heat urban fluxes will be implicitly taken charges through their effects on the temperature and humidity.

One of the CG lightning parameterization applications is to know the relationship between the forest fire occurrences and the climate change scenarios. Since the CG lightning is a dominant factor to forest fire ignition, its frequency tendency influencing strongly the smog emission and the aerosol concentrations. The forest fire smog increases the condensation nucleus concentration in clouds $[65,12,40]$ and change the cloud albedo and precipitation comportment [66,39]. Using the forest fire indexes [3] and the explicit treatment of aerosols in NARCM $[18,19]$, the CG lightning parameterization will be allow as to investigate the aerosol effects in the climate. Also, with combining the CG lightning parameterization in NARCM [52], this strategy will be allow as to establish an interactive link with the smog emission and the retroaction with the atmospheric circulation and the climate from perturbation on simulated climate.

\section{Data}

The local climate model (LCM) used in this study [54] is a column version of the regional climate model $[9,10,32]$ and the global climate model [31]. The LCM is controlled by the lateral transport of the prognostic variables through the border areas. The simulated physical processes 
include radiation, hydrology, the convection, topography, the boundary layer and the surface heat flows. These parameters are recalculated from the global climate model (MGC) routines for each time step of the model (20 minutes). This model uses the Canadian Land Surfaces Scheme (CLASS) [70,71] to illustrate the vegetation influence on the surface energy budget. CLASS simulates the hydrographical processes including the evaporation, the transpiration, the infiltration, the sensible and latent heat flows and the radiation. It simulates the temperature and humidity on a vertical profile starting from surface until a depth of $3.75 \mathrm{~cm}$ in the ground. At the same time, dynamic climate of the ground calculated by CLASS, product feedbacks interactively with the basic variables of LCM. The coupled system atmosphere-ground produces a climate on a column starting from the ground to the stratosphere high level $(100 \mathrm{hPa})$. Starting from LCM model, we used the aerological data of Maniwaki covering sixteen years period, from 1988 to 2004 . These data are treated by a program interpolating the aerological data, from the surface to $100 \mathrm{hPa}$ level to assimilate data and the dynamic tendencies evolution of the temperature, moisture, the wind and the pressure.

To develop a CG lightning parameterization, two selected data are used: 1) the hourly data of CG lightning for May to August period from sixteen years (1988 to 2004), in a $100 \mathrm{~km}$ radius around, Maniwaki, and 2) interpolated atmospheric data from LCM at Maniwaki station. We have 47232 hours of measurement data equivalent to 1968 days with electric activity. 167417 CG lightning impacts were recorded during this period. This recover CG lightning resolution is used, since is adequate to global and regional climate models. The actual climate models resolution is about $100 \mathrm{~km}$ around a point $[37,63,15,51]$. We are choice this scale as a resolution reference. Since the selected data are robust, we will demonstrate that the choice of one station is adequate to define an applied parameterization at all Canadian domain.

In order to validate this CG lightning parameterization on independent regions, we will have applied to four distinct areas in Canada for the same periods from May to August, for six years 
(1999-2004). We chose these areas where they are distributed on a vast territory, from the west to the east to provide independent tests on the Canadian domain.

\section{Hypothesis}

Although there are several theoretical studies speaking about the electric phenomena such as the theory of the fine precipitation droplets collision with the selective ions capture $[44,45,2]$, we found Williams [76] who developed a simple lightning parameterization using the cloudy column thickness on basis of the theoretical electric equations, frequency and standard aerological data. Price and Rind [68] used this parameterization, applicable at continental regions, to develop it at maritime regions to compare the total lightning at actual and climate change scenarios at global scale. Soriano et al. [50] analyzed the relationship between the flash density and the number of thunderstorm days, using the aerological data of $12 \mathrm{~h}$ TU from 168 days at Madrid, Spain. They used a statistical method to deduce the correlation between the CG flash density, dew-point temperature at $850 \mathrm{hPa}$ and temperature difference between $850 \mathrm{hPa}$ and $700 \mathrm{hPa}$. Also, Devendraa et al. [42] explain that the vertical profiles of temperature and moisture represents two main parameters to convection development in the atmosphere where the wind vertical profile influences the structure, evolution and movement convectif in the atmosphere.

To study the meteorological parameters comportment with the CG lightning occurrence, we use the Solomon et al. [49] hypothesis, where confirmed a strong dependence between the temperature, the water content and the electric charge transfers inside thunderstorm. Also, to have the best results, we are tested many implied parameters in this processes. We chose the 
dew-point temperature of the $850 \mathrm{hPa}$ level (Td850) and the precipitable water content (PWC) to represent the water contents in the convective cloud. We selected the temperature difference between $850 \mathrm{hPa}$ and $700 \mathrm{hPa}$ levels (T700), between $850 \mathrm{hPa}$ and $500 \mathrm{hPa}$ levels (T500), between the surface and $200 \mathrm{hPa}$ level (T200), the convective available potential energy (CAPE), and the freezing level altitude (FLA) to represent the temperature of the convection.

After analyses, we found that the freezing level altitude (FLA) and the precipitable water content (PWC) as being the best parameters to characterize the CG lightning activity in the CRCM. The results obtained give a better correlation for these two parameters (PWC and FLA) with the monthly CG lightning frequency and occurrence during the 16 years period of studies (Table 1).

Table 1.1: Monthly CG lightning occurrence (a, OCC) and frequency $(b, F)$ correlation with the selected parameters: dew-point temperature of the $850 \mathrm{hPa}$ level (Td8), precipitable water content (PWC), temperature difference between $850 \mathrm{hPa}$ and $700 \mathrm{hPa}$ levels $(\mathrm{T} 700)$, temperature difference between $850 \mathrm{hPa}$ and $500 \mathrm{hPa}$ levels (T500), temperature difference between the surface and $200 \mathrm{hPa}$ level (T200), the convective available potential energy (CAPE), and the freezing level altitude (FLA).

(a)

\begin{tabular}{llllllll}
\hline OCC & Td8 & PWC & FLA & T700 & T500 & T200 & CAPE \\
\hline$r$ & 0.48 & 0.80 & 0.54 & -0.13 & -0.21 & 0.24 & 0.52 \\
\hline
\end{tabular}

(b)

\begin{tabular}{llllllll}
\hline$F$ & $T d 8$ & $P W C$ & $F L A$ & $T 700$ & $T 500$ & T200 & CAPE \\
\hline$r$ & 0.49 & 0.50 & 0.51 & 0.10 & 0.11 & 0.32 & 0.50 \\
\hline
\end{tabular}

This indicates that other factors not considered have an important influence. We already identified that the microphysics of the precipitation and the clouds are in question and should be considered in a future version of CRCM, when these variables are explicitly treated in a predictive way. They are however not available in the current version, which causes to limit the CG lightning parameterization reliability. The parameterization which we selected represent 
the essential conditions but insufficient for the CG lightning occurrence. To treat rigorously the CG lightning, it is necessary to include the equations of the electric charges budget in the dynamics of the model $[47,48,26]$. However, these predictive equations must be solved on spatial and temporal scales inaccessible by the climatic models, from where need for folding back itself on a CG lightning parameterization.

The freezing level altitude (FLA) and the convective available potential energy (CAPE) presented respectively two nearly linear correlation coefficients (Table 1). Since they represent respectively the potential energy of the atmospheric layer under the freezing level and these of the convection available, it is clearly that their linear correlation coefficients with the CG lightning are almost similar. The use of the FLA instead of the CAPE was selected for the flexibility and its calculation reliability cause from the climatic models diagnostic data. The freezing level altitude (FLA) is calculated from LCM geopotential levels corresponding to positive and negative temperature immediately. The precipitable water content (PWC) is calculated using a vertical integration of the total humidity content from an atmospheric column surface of a $1 \mathrm{~m}^{2}$. These two parameters are calculated from the LCM diagnostic data. Although about half of the precipitable water content is below the $850 \mathrm{hPa}$ level (nearly altitude of 1500 meters), our correlation tests with the CG lightning frequency suggest the use of the total precipitable water content in the atmosphere representing the lightning conditions. That enables us to not discriminate the water quantity above the $850 \mathrm{hPa}$ level.

\section{Results}

Many researches indicates that the CG lightning frequency is related to the weather conditions $[28,30,59]$, to geographic or orographic factors [50,53], and to atmospheric electricity $[48,26]$. Although our hypothesis is based on the precipitation theory related to the microphysical 
processes of the electric charges composition in the cloud convection, we limit this research to the climatic parameters study related to the CG lightning type. The complexity of the microphysical processes in the atmosphere does not enable to us to include the electric parameters explicitly in this study. For that reason the CG lightning is very complex. Indeed, the electric characteristic depends of sizes and droplet water number in convective clouds [47,49]. Thus, the momentary intense updraft motion [59] and the precipitation mechanisms [8] have a direct effect in lightning occurrence and frequency. For our case, the temperature and the moisture content, presenting our reference data, have a direct influence to electric charge formation in convective cloud [50].

The figures 1(a) and 1(b) shows respectively the hourly variation of the freezing level altitude (FLA) with the precipitable water content (PWC) in absence and presence of CG lightning. Generally, a high level of FLA is characterized by a maximum of precipitable water content thus forming a static instability where the CG lightning could appear. On the other hand, a low level of FLA supports the stable atmospheric conditions and the precipitable water content decreases. This last condition disadvantages the CG lightning occurrence or decreases its frequency. Figures 1(c) and 1(d) confirm this observation where more than $60 \%$ of the higher FLA and PWC cases are characterized by high CG lightning frequencies and occurrences.

Is not rare to found the atmospheric unstable condition in presence of an important quantity of humidity without CG lightning occurrence where the figure 1(a) shows these conditions. Solomon et al. [49] confirmed the possibility absence of CG lightning occurrence in atmospheric convection. They explained that the complexity of microphysics processes in thunderstorm is the principal cause of absence or presence of lightning.

Since it is impossible to include the microphysical effects of convective clouds on the lightning parameterization, like the cloud structure (size, a droplet number and particle phases), we used 
a statistical relationship of the convection static state and its water content to determine the CG lightning occurrence and frequency. As it was explained before, we found that the combination of the freezing level altitude (FLA) with the precipitable water content (PWC) presents the best result using the monthly CG lightning parameterization.

To study the dependence of the CG lightning occurrence and frequency with the climate, the hourly, the mean daily and the mean monthly data during May-August of sixteen years at Maniwaki are analyzed. The CG lightning frequency represents the number of instantaneous impacts whereas its occurrence describes the number of hours with the lightning. Since, the hourly and daily correlation of the CG lightning frequency with climatic parameters is weakly, we limit our calculations with the mean monthly data. The application of various types of correlation showed us a better result with the linear method. This choice enables us to stabilize our results compared to the observations, which is not the case for the exponential correlation where its results can be converged quickly to the extremely high values of FLA and PWC (figure 2(a) and 2(b)), causing an imbalance compared to the observations. The utility of the statistical link is to quantify the CG lightning from the climatic parameters characterizing the mean convection. We will explain further the weakness cause of the hourly and daily correlation between the climatic data and the CG lightning.

Firstly, we correlate the monthly CG lightning occurrence (OCC, events month ${ }^{-1}$ ) with the mean monthly freezing level altitude (FLA) and the mean monthly precipitable water content (PWC) $[34,43]$. Their parameterization is presented as

$$
\mathrm{OCC}=16^{*} \mathrm{FLA}+2.5 * \mathrm{PWC}-51
$$

$$
\mathrm{n}=64, \mathrm{p}<0.001
$$


The spatial distribution of OCC compared to the corresponding FLA and PWC are presented at figure 3(a). Their correlation coefficients are respectively 0.54 and 0.80 . This relationship is presented by aligned straight lines in this figure.

Secondly, the statistical correlation $[34,43]$ between the monthly CG lightning frequency (F, impacts month $^{-1}$ ), the mean monthly freezing level altitude (FLA) and the mean monthly precipitable water content (PWC) defined as

$$
\begin{aligned}
& \mathrm{F}=951 * \mathrm{FLA}+101 * \mathrm{PWC}-3453, \\
& \mathrm{n}=64, \mathrm{p}<0.0001
\end{aligned}
$$

The figure 3(b) shows the spatial distribution of $\mathrm{F}$ compared to the corresponding FLA and PWC. Their correlation coefficients are respectively 0.51 and 0.50 . This relation is presented by aligned straight lines in this figure.

The figure 4(a) shows a comparison between the CG lightning occurrence calculated from the preceding equation and the observations. Their distribution presents a better correlation coefficient. The mean absolute error rate is equal to $27 \%$ compared to the mean observed data. Indeed, the CG lightning occurrence, constitute one event for one hour with lightning without consider its frequency, will reflect with advantage the climatic conditions. The great variability, presented in the CG lightning frequency, will be eliminated through its occurrence. The microphysical process effects causes mainly the large variability of the CG lightning frequency, where it is not appears for the occurrence. It is for that reason the CG lightning occurrence variability does not present high variations like that with the frequency compared to the equivalent observed data (figures 5(a) and 5(b)).

The figure 4(b) shows a comparison between the CG lightning frequencies calculated from the preceding equation and the observations. Their distribution presents a weak correlation 
coefficient. The mean absolute error rate is equal to 55\% compared to the mean observed data. The observed CG lightning frequency varies largely comparatively to the simulated data, presenting an over-estimate for the weak frequencies and an under-estimate for the high frequencies (figure 4(b)). Their temporal evolution presents proportionality between them (figure 5(b)). Since the CG lightning frequency depends essentially to the electric capacity in the cloud, the microphysical processes influence directly this effect like the particles evolution of the electric charges in the convection and their spatial and temporal distribution since they are the origin of the lightning occurrence. The missing of the electric knowledge ignites the CG lightning and their representation in the model is a significant handicap causing this difference.

Also, it is possible to estimate the monthly day's number with CG lightning (JJ, days month ${ }^{-1}$ ) from its monthly occurrence (OCCM, events month $\left.{ }^{-1}\right)$. The statistical equation is established as follows

$$
\mathrm{JJ}=0.12 * \mathrm{OCCM}+4.65
$$

$$
\mathrm{n}=64, \mathrm{p}<0.001
$$

with a correlation coefficient of 0.82 ,

To test this parameterization, we applied this formulation during the sixteen study years. The figure 5(c) shows the temporal calculated and observed variation of monthly days numbers with CG lightning. The results show the same variability compared to the equivalent observed data like as with occurrence. The mean absolute error rate is equal to $24 \%$, compared to the mean observed data.

In a second phase, we applied this parameterization (formulation 1 and 2) with the mean daily data during the sixteen years period in order to recalculate the monthly results. This method 
permitted us to find again the same monthly results of the CG lightning occurrence and frequency with a very high correlation coefficient (figures 6(a) and 6(b)). That confirmed us the monthly calculation was preserved with the CG lightning parameterization application to the daily data.

For the four Canadian regions (figure 7) and for the same periods from May to August and for six years (1999-2004), the monthly CG lightning occurrence and frequency variation calculation compared to the observation shows the same variability as that of Maniwaki (figures 8 (a) and $8(\mathrm{~b})$ ). The mean absolute error rate is between $27 \%$ and $39 \%$ for the occurrence, between $49 \%$ and $57 \%$ for the frequency and between $21 \%$ and $35 \%$ for the numbers of days with CG lightning compared to the observation. Thus, we note an over-estimate for the weak frequencies and an under-estimate for the high frequencies in these regions like as with Maniwaki. As it was explained before, the CG lightning frequency increases quickly in climate characterized by a very unstable condition and with maximum humidity than the parameterization is not able to calculate them. In the same way, the missing of the electric knowledge in the clouds represents a constraint of the CG lightning parameterization.

Lastly, the use of the CG lightning parameterization showed that the monthly CG lightning occurrence and frequency using the daily and monthly climate data are similar for the four areas tested (respectively figures 9(a) and 9(b)). That confirms us the daily results are representative with monthly calculations. In the next section, we will discuss the CG lightning parameterization while referring to the physical processes of the convection in the atmosphere.

\section{Discussion}

From the freezing level altitude (FLA), representing a critical level where the water vapor will be transformed to liquid or solid state (condensation phenomena), the electric charges 
beginning formed. The light particles (water droplets and ice crystals) are raised under the action of the unstable updraft motion inside the convective cloud. They electrified positively following several complex processes, while the heavy particles (water drops and hails) move to the lower cloud level while taking electrified negatively $[16,75,11,57]$. The electric charges will be formed, causing the CG lightning occurrence when the electric potential between the bottom cloud and the ground becomes important.

The application of the Solomon et al. [49] hypothesis at Maniwaki region during the MaiAugust period of sixteen study years confirmed the relationship between the CG lightning occurrence and the air instability, equivalent to a higher freezing level altitude (FLA), and an important quantity of precipitable water. Indeed, the figure 1(b) confirmed this observation. In these conditions, the statistical computing presented a mean daily CG lightning frequency of 180 impacts per day, equivalent to a mean daily CG lightning occurrence of 4 events per day. On average, 8 days from 12 per month characterized by CG lightning occurrence, equivalent to a mean probability of $67 \%$.

However, it is not rare that these conditions can present without CG lightning where figure 1(a) shows this observation. Solomon et al. [49], using the microphysical processes at a storm development, confirm that the convection could produce or not the CG lightning. In an opposed way, the electric charges formed in a storm can produce the CG lightning in atmospheric conditions characterized by a low freezing level altitude and a no significant quantity of precipitable water. In this case, the CG lightning frequency could be weak. We noted this observation in figure 1(b) where the CG lightning appears with a weak CG lightning frequency, generally equivalent to a mean of one impact per hour, or a mean of 17 impacts per day. The electric charges formed in these conditions, can produce the CG lightning where our parameterization could not product it. The complexity of the microphysical processes inside the storm is the mainly cause for our parameterization difficulty, not considered here. 
Although our parameterization is conceived to quantify the CG lightning, it becomes essential to be based on statistical correlations between its occurrence and the climatic conditions on the one hand, and between its frequency and the same climatic conditions on the other hand. Our objective was to determine a better correlation between the simulation and the observation data. Figures 5(a), 5(b) and 5(c) have these results with a mean absolute error rate of $27 \%, 55 \%$ and $24 \%$ for the occurrence, frequency and monthly numbers of days with CG lightning respectively.

The monthly computing showed that the CG lightning occurrence is correlated better than the frequency to be comparable to the observation data (figures 4(a) and 4(b)). Indeed, the computed CG lightning frequency varies proportionally with the equivalent observed data, presenting sometimes a notable difference between them, the case of July for the years 1993 , 1994, 1999 and 2001 (figure 5(b)). These differences represent under-estimations of the CG lightning frequency mentioned in figure $4(\mathrm{~b})$ and presented by points below the diagonal. It is almost difficult that the climatic conditions can identify this variation exactly. The absence of the electric effect in the $\mathrm{CG}$ lightning parameterization, related mainly to the cloud microphysical processes, is the principal cause of this variability. On the other hand, the CG lightning occurrence is better comparable to the equivalent observed data, excluded than of July of the years 1993, 1994, 1996 and 1998, presenting high errors (figure 5(a)), due mainly to occurrences characterized by weak frequencies that the CG lightning parameterization cannot detected. These same under-estimations of the CG lightning occurrence and frequency are also presented on four Canadian areas (figures $8(\mathrm{a})$ and $8(\mathrm{~b})$ respectively). The simulated occurrence (figure 8(a)) is compared favorably with the observations that its frequency at all stations as in Maniwaki.

The application of the CG lightning parameterization on Maniwaki region and on four Canadian areas, using the daily data, presented the same monthly results compared to the CG lightning 
parameterization results, using the monthly data (figures 6(a) and 6(b), and figures 9(a) and 9(b)). That enables us to use the CG lightning parameterization with the regional climate models to evaluate its spatial distribution and temporal variation compared to the observed data. It is very interesting to evaluate these results in a context of climate changes.

\section{Conclusion}

The CG lightning parameterization was developed using the diagnostic data of the Local Climate Model (LCM). The atmospheric variables, characterizing the convection during the May-August period of sixteen years in Maniwaki region (located in the south-western Quebec), were analyzed with the CG lightning occurrence and frequency. The freezing level altitude and the precipitable water content were selected to develop a CG lightning parameterization. The dependence between the freezing level altitude and the precipitable water content in presence and absence of CG lightning was presented. Then, a CG lightning occurrence and frequency parameterization was developed. Lastly, the application of this parameterization in Maniwaki and four Canadian regions was analyzed. The principal results are as follows:

Firstly, the analysis of the various climatic parameters showed that the freezing level altitude and the precipitable water quantity are the best parameters to characterize the CG lightning occurrence in the CRCM. Although other factors related to the clouds and precipitation microphysics are not considered in this study, for the cause of no availability in the CRCM. These climatic parameters chosen represent necessary conditions but no sufficient for the CG lightning occurrence.

Secondly, the knowledge of the freezing level altitude and the precipitable water quantity permit as to computing the CG lightning occurrence and frequency at monthly scale. A comparison between the observations and simulations showed a reasonable correlation, considers the 
difficulty level in cause, the monthly CG lightning occurrence and frequency with a mean absolute error rate of $27 \%$ and $55 \%$ respectively. The microphysical processes, since they represent important mechanisms with the CG lightning frequency, are the principal source of these errors, not considered in our CG lightning parameterization. This is the principal inaccuracy factor of the CG lightning parameterization at daily and monthly scales. However, the application of this CG lightning parameterization to daily data, help us to re-find the monthly results. The application of the parameterization in four Canadian regions showed the same conclusions like as with Maniwaki, confirming the robustness of this parameterization on Canada.

Since the monthly results showed proportionality with the equivalent observed data, it become difficult to compute exactly the CG lightning occurrence and frequency for the absence of the electric processes in our parameterization. This parameterization will give as best results in a context of climate change scenarios.

Lastly, an additional work must be developed in a large domain to study the robustness of the CG lightning parameterization with the regional numerical models, which will be the subject of the next stage. It would be also interesting to determine how this method can be applied to regions other than Canada but comparable to climatic condition such Siberia and Europe. In conclusion, this parameterization will also make it possible to improve research on the effect between forest fire indexes, the CG lightning occurrence and frequency variability on the current climate and the climate changes following the greenhouse gases, aerosols and vegetation changes. 

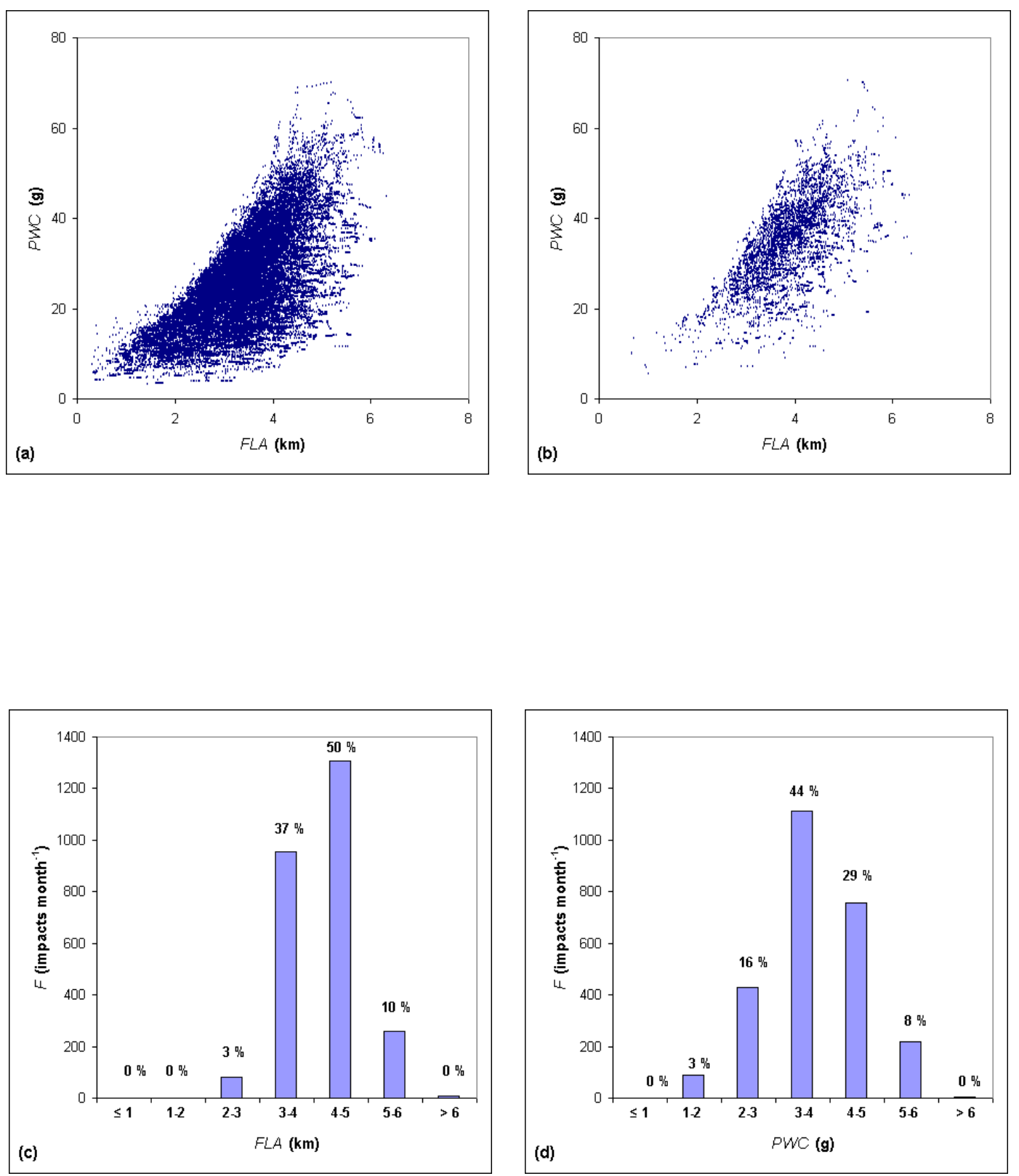

Figure 1 Variation of the hourly freezing level altitude (FLA) with the precipitable water content (PWC) in a) absence and b) presence of CG lightning at Maniwaki, during May-August period of 1988-2004 years (16 years, excluding 1991). The figures (c) and (d) illustrate the observed monthly mean CG lightning frequency variation according to the freezing level altitude (FLA) and the precipitable water content (PWC) respectively. 
(a)

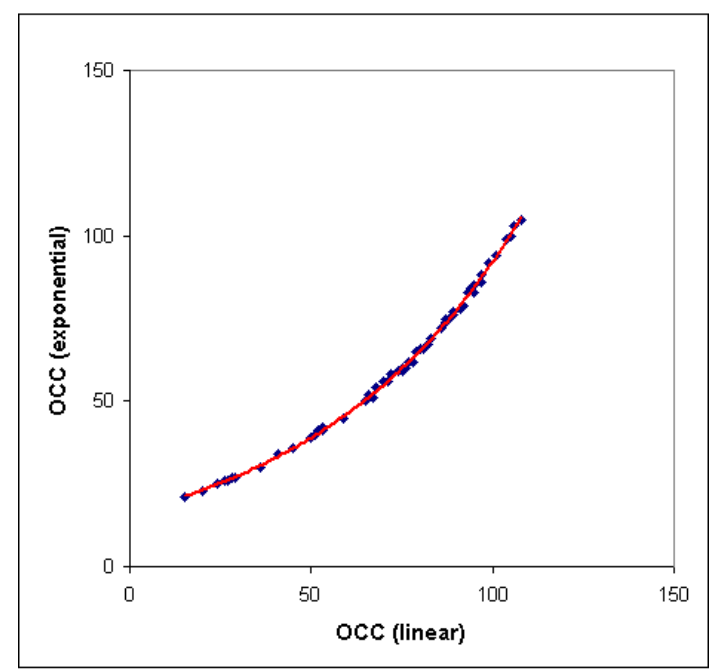

(b)

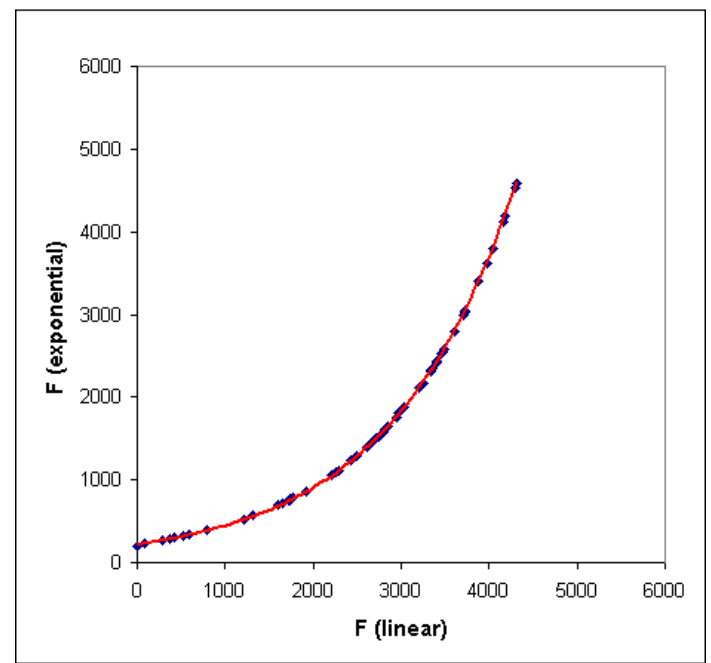

Figure 2 Evolution of the CG lightning a) occurrence (OCC) and b) frequency (F) parameterization using the linear and exponential methods at Maniwaki, during May-August period of 1988-2004 years (16 years, excluding 1991).

(a)

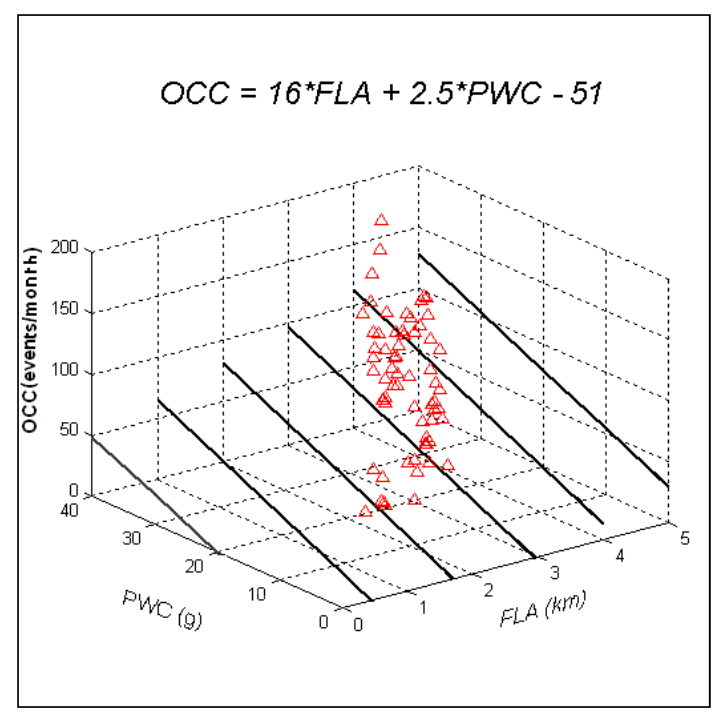

(b)

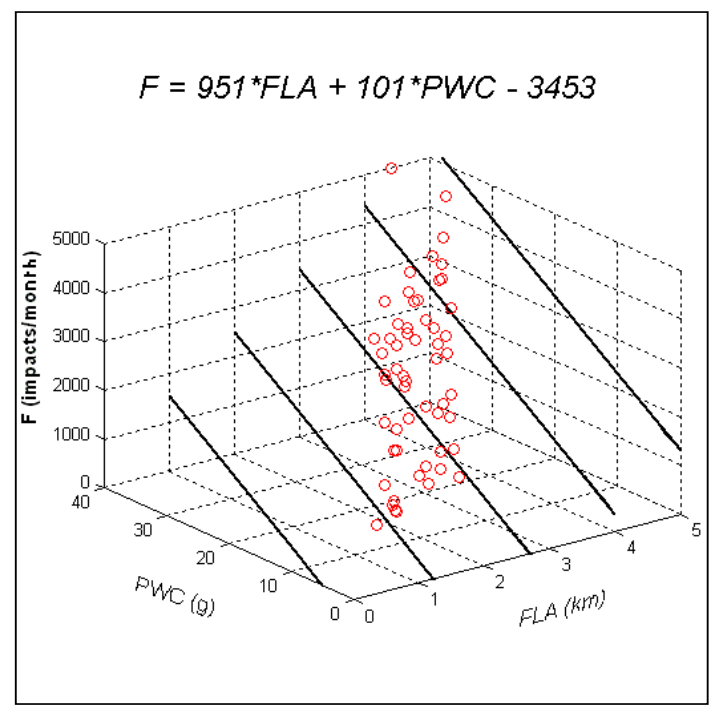

Figure 3 Variation of the monthly mean CG lightning occurrence (OCC, (a)) and frequency (F, (b)) according to the freezing level altitude (FLA, km) and the precipitable water content (PWC, g) at Maniwaki, during May-August period of 1988-2004 years (16 years, excluding 1991). The straight lines in (a) and (b) represents the linear correlation of PWC and FLA with OCC and F respectively. The observed data presented by the o and $\Delta$ symbols for OCC and F respectively. 
(a)

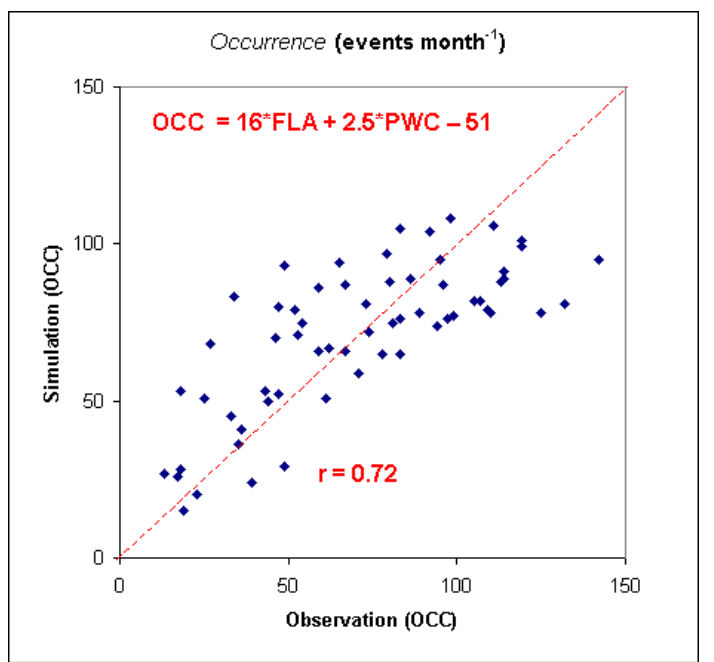

(b)

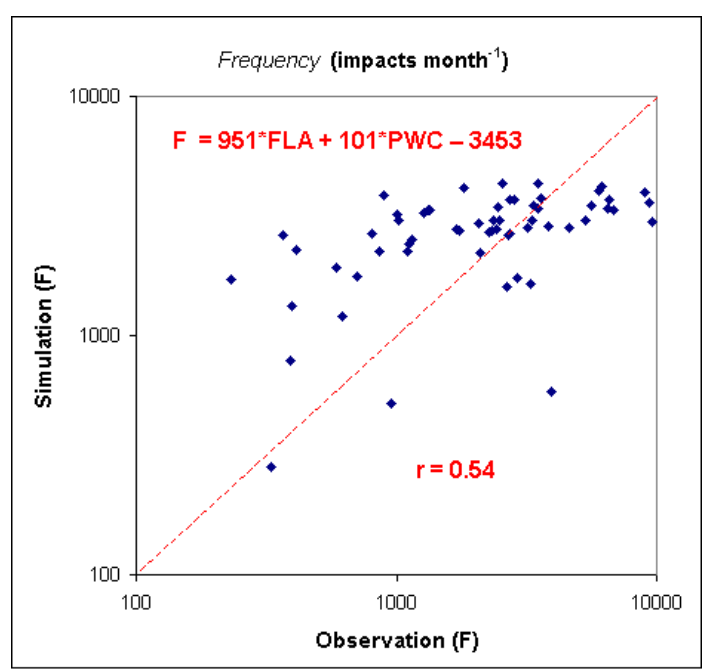

Figure 4 Variation between the simulated and observed monthly CG lightning a) occurrence $\left(\mathrm{OCC}\right.$, events month $\left.{ }^{-1}\right)$ and b) frequency $\left(\mathrm{F}\right.$, impacts month $\left.{ }^{-1}\right)$ at "Maniwaki" during MayAugust period of 1988-2004 years (16 years, excluding year 1991).

(a)

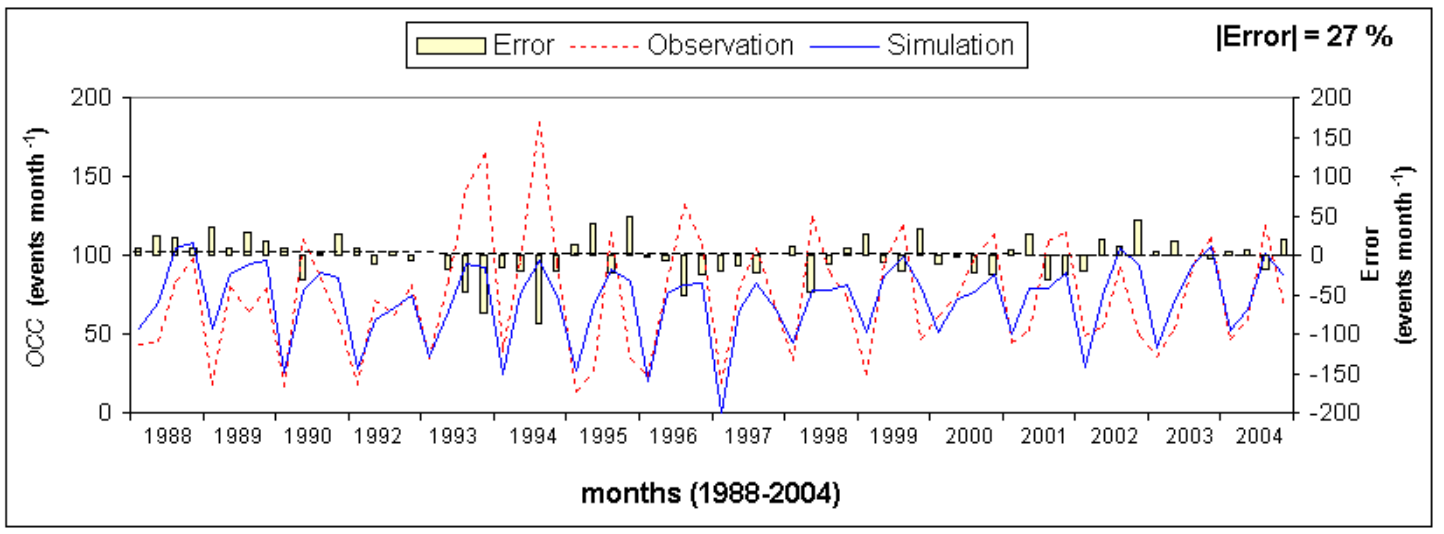

(b)

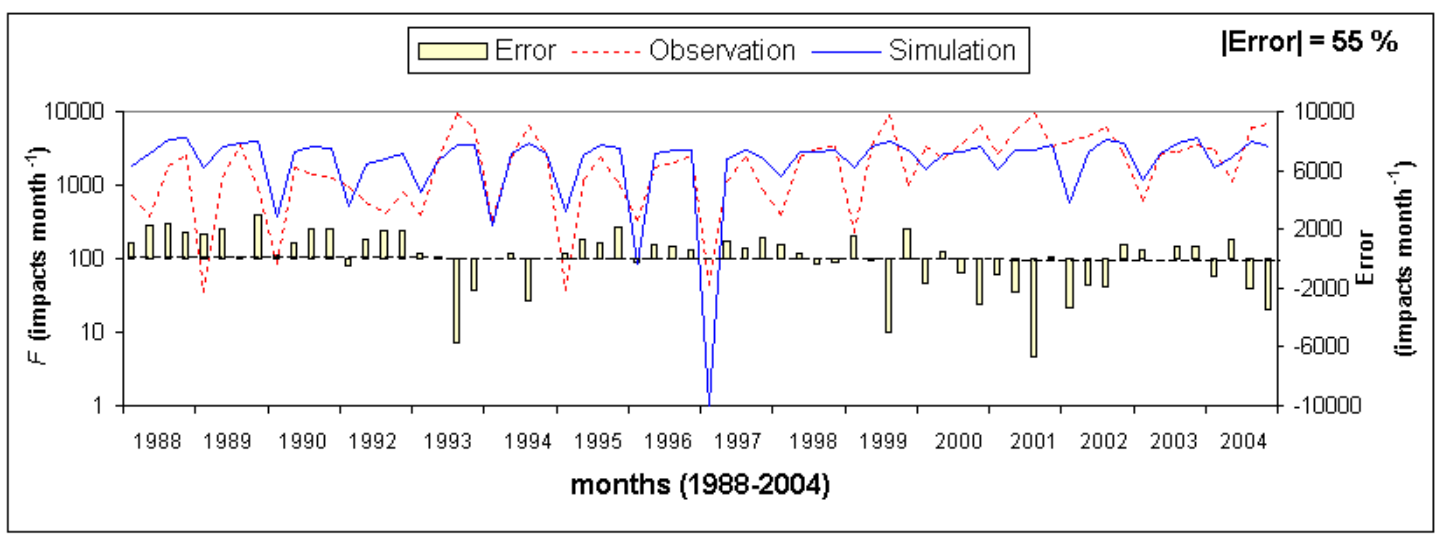


(c)

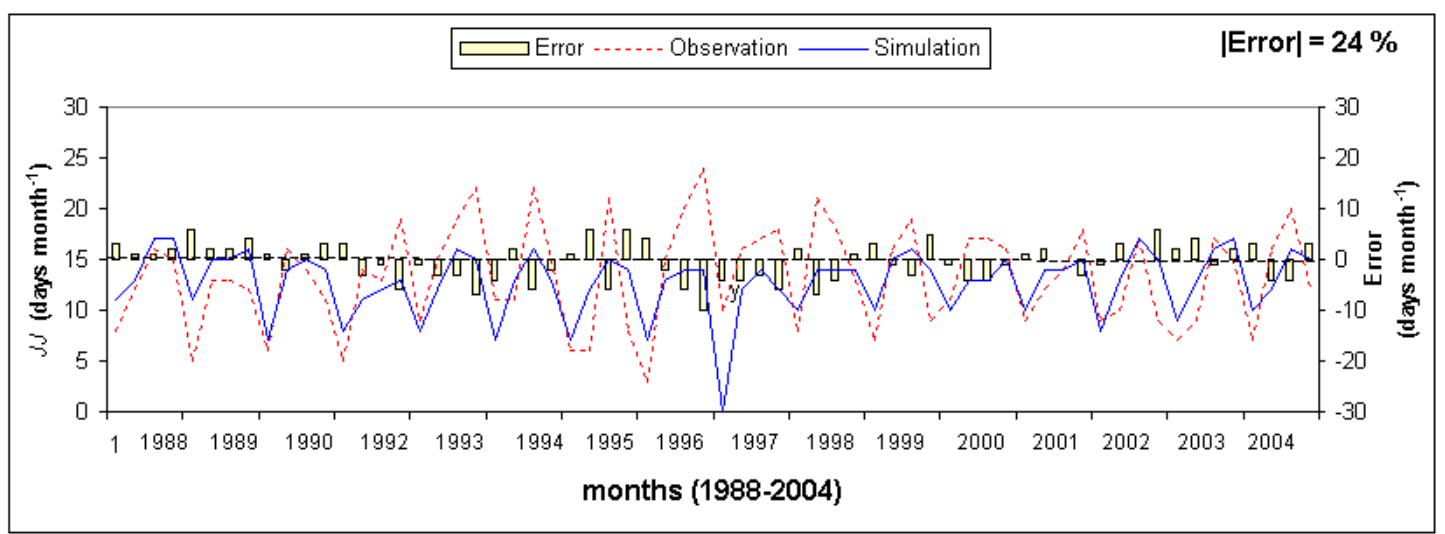

Figure 5 Monthly evolution of the CG lightning a) occurrence, b) frequency and c) days number with CG lightning, at "Maniwaki" during May-August period of 1988-2004 years (16 years, excluding year 1991). The stick curve represents the difference between simulated and observed monthly results (Error).

(a)

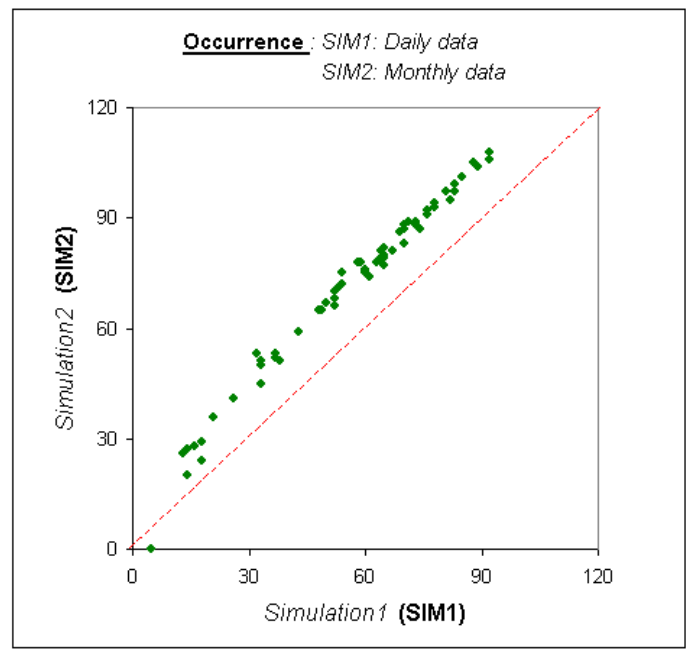

(b)

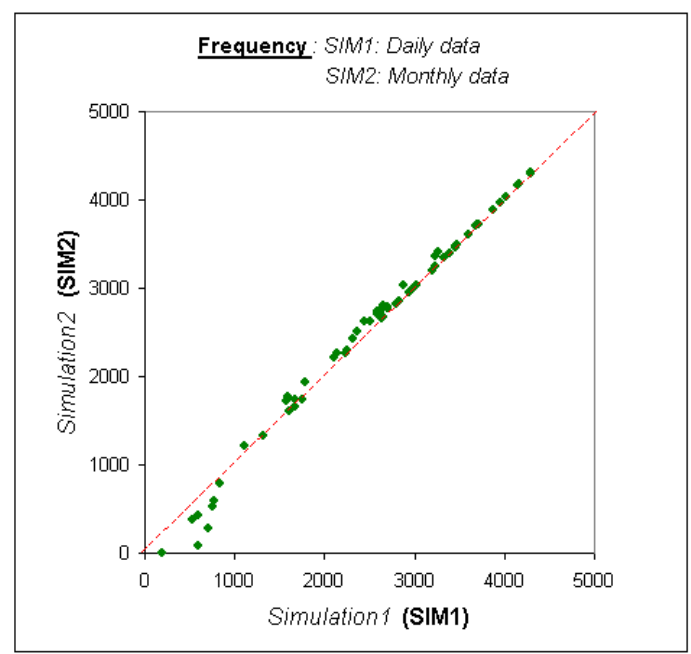

Figure 6 Variation between two simulated results of the CG lightning: a) occurrence and b) frequency at "Maniwaki" region during May-August period of 1988-2004 years (16 years, excluding 1991). The simulation 1 and 2 (SIM1 and SIM2) illustrates respectively the CG lightning parameterization applied to daily and monthly means. 


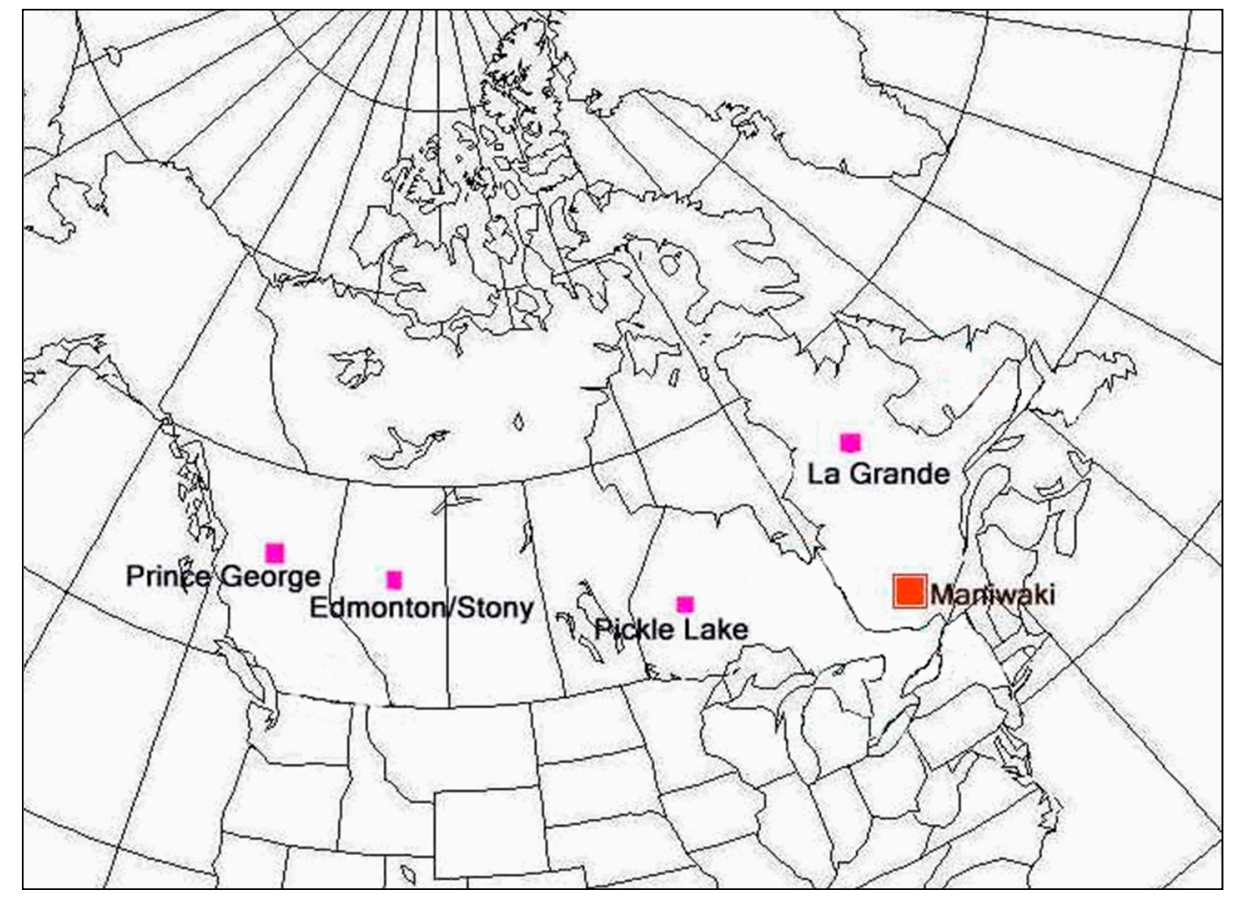

Figure 7 Canadian areas map where the CG lightning parameterization is verified.

(a)

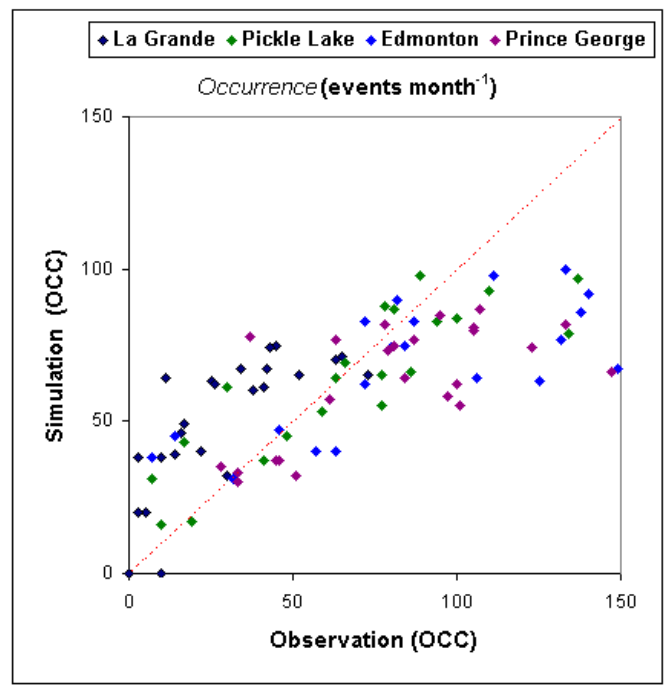

(b)

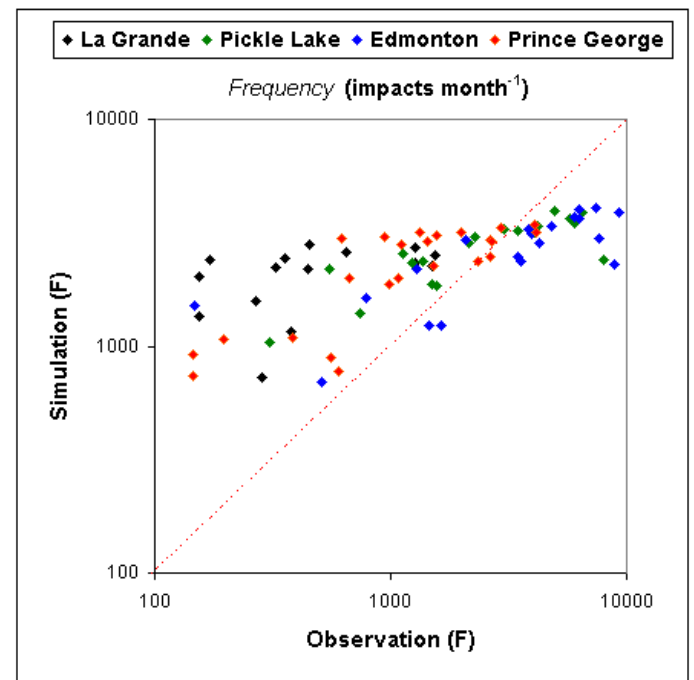

Figure 8 Variation between the simulated and observed results of the CG lightning a) occurrence and b) frequency at "La Grande", "Pickle Lake", "Edmonton" and "Prince George" during May-August period of 1999-2004 years (6 years). 
(a)

(b)
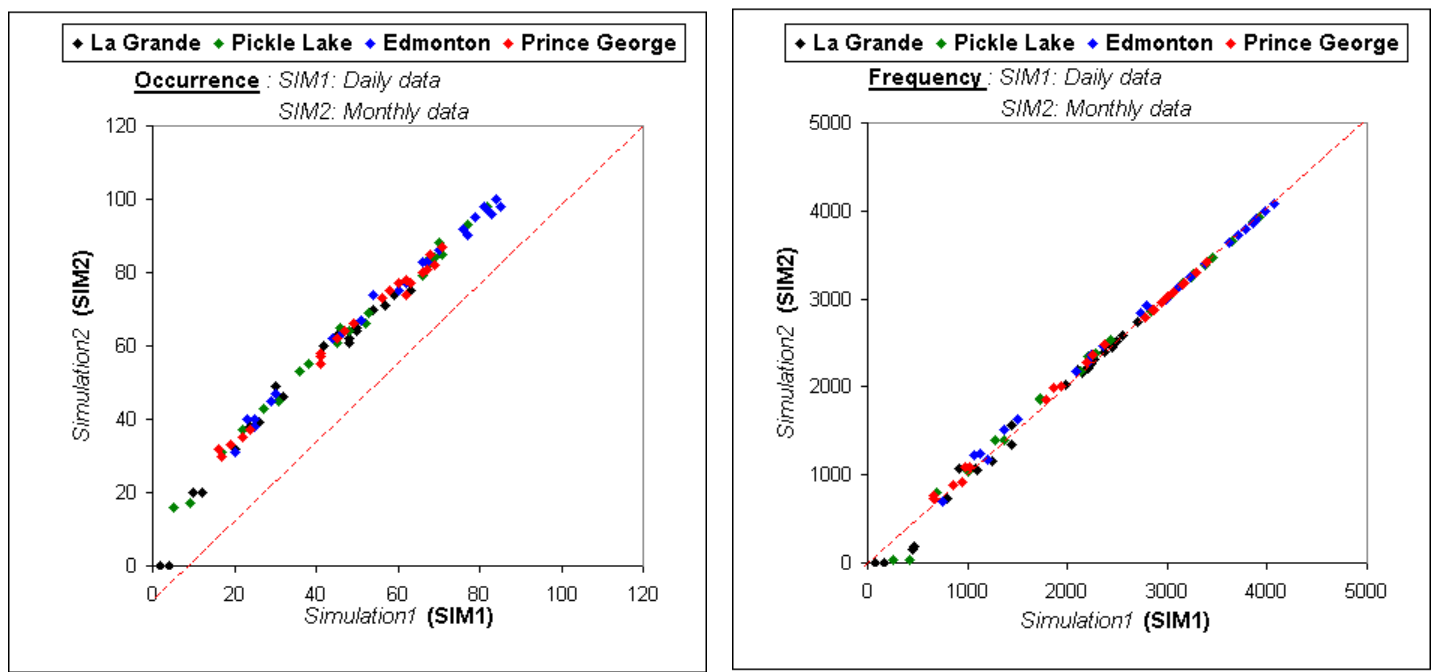

Figure 9 Variation between two simulated results of the CG lightning a) occurrence and b) frequency at "La Grande", "Pickle Lake", "Edmonton" and "Prince George" region during MayAugust period of 1999-2004 years (6 years). The simulation 1 and 2 (SIM1 and SIM2) illustrates respectively the CG lightning parameterization applied to daily and monthly means.

\section{References}

1. Anderson R. B., Erickson A. J. Lightning parameters for engineering application. Electra. 1980, 69: 65-102.

2. Arif A. La foudre dans l'atmosphère: l'avenir de notre énergie en 2050. Éditions Universitaires européennes, ISBN: 978-3-8381-8304-6. 2014, 96 pages.

3. Arif A. Climatologie des indices de feux de forêts avec les Modèles Climatiques Canadiens (MLC et MRC). Éditions universitaires européennes. ISBN: 978-613-153592-5. 2012, 136 pages.

4. Bergeron Y., Flannigan M. D. Predicting the effects of climate change and on fire frequency in the Southeastern Canadian Boreal forest. Weather, Air and Soil pollution. 1995, 82: 437-444. 
5. Bergeron Y. Les conséquences des changements climatiques sur la fréquence des feux et la composition forestière au sud-est de la forêt boréale québécoise. 1998. Vol. 52, nº 2: $167-173$.

6. Bergeron Y., et al. Natural fire frequency for the eastern Canadian boreal forest: Consequences for sustainable forestry. Can. J. For. Res. 2001, 31: 384-391.

7. Blustein H. B., MacGorman D. R. Evolution of Cloud-to-Ground Lightning Characteristics and Storm Structure in the Spearman, Texas, Tornadic Supercells of 31 May 1990. Ame. Meteorol. Soc. 1998, 1451-1467.

8. Carey L. D., Rutledge S. A. Electrical and multiparameter radar observations of a severe hailstorm. J. Geophys. Res. 103: 1998, 13 979-4 000.

9. Caya, D., R. Laprise, M. Giguère, G. Bergeron, J. P. Blanchet, B. J. Stocks, G. J. Boer, and N. A. McFarlane. Description of the Canadian regional climate model. Water, Air and Soil Pol., 82. 1995, 477-482.

10. Caya, D., R. Laprise. A Semi-Implicit Semi-Lagrangian Regional Climate Model: The Canadian RCM. Month. Weath. Rev, 127. 1999, 341-362.

11. Chiu C. S., Klett J. D. Convective electrification of clouds. J. Geophys. Res., 81. 1976, $1111-1124$.

12. Chuang C. C., Penner J. E., Edwards L. L. Nucleation scavenging of smoke particles and simulated drop size distributions over large biomass fires. Journal of the Atmospheric Sciences, Vol. 49. 14. 1992, 1264-1275.

13. Conseil Canadien des Ministres des Forêts. Critères et indicateurs de l'aménagement durable des forêts au Canada. Ottawa. 2000, 125 pages. 
14. Dale V. H., et al. Climate change and forest disturbances. Bioscience: 51 (9). 2001, $723-$ 734.

15. Denis B., Laprise R., Caya D. Sensitivity of a regional climate model to the resolution of the lateral boundary conditions. Climate Dynamics: 20. 2003, 107-126.

16. Elster J., Geitel H.,. Über eine Methode, die elektrische Natur der atmosphärischen Niederschläge zu bestimmen (About a method for determining the electric nature of atmospheric precipitation). Meteor. Z., 5. 1888, 95-100.

17. Granström A. Spatial and Temporal Variation in Lightning Ignitions in Sweden. Journal of Vegetation Science, Vol. 4. 1993, 737-744.

18. Gong S. L., Barrie L. A., Lazare M. Canadian Aerosol Module (CAM): A sizesegregated simulation of atmospheric aerosol processes for climate and air quality models, 2, Global sea-salt aerosol and its budgets. Jour. of Geophy. Resea., Vol. 107, NO. D24. doi: 10.1029/2001JD002004. 2002.

19. Gong S. L., et al. Canadian Aerosol Module: A size-segregated simulation of atmospheric aerosol processes for climate and air quality models, 1, Modele development. Jour. Of Geophy. Resea., Vol. 108, NO. D1, doi. 10.1029/2001JD002002. 2003.

20. Greene J. S., et al. Relationships between Synoptic Climatology and Atmospheric Pollution at 4 US Cities. Theor. Appl. Climatol., 62. 1999, 163-174.

21. Grelle A., et al. Evaporation components of boreal forest: Variations during the growing season. Jour. Hydrology 197. 1997, 70-87. 
22. Guyette R. P., Muzika R. M., Dey D. C. Dynamics of an Anthropogenic Fire Regime. Ecosystems, 5. 2002, 472-486.

23. Hall, J. P. Effects of acidic deposition on Canada's forests. Information report ST-X / Canada. Forestry Canada, v, 25. 1998, 23 p.

24. Hauf T. Lightning statistics for southern Germany. Institut for Physik der Atmosphere des DLR, Oberpfaffenhofen, 1997.

25. Huffines G. R., Orville R. E. Lightning ground flash density and thunderstorm duration in the continental United States: 1989-96. J. Appli. Meteorol., 38. 1999, 1013-1019.

26. Qie X., et al. Charge analysis on lightning discharges to the ground in Chinese inland plateau (close to Tibet). Ann. Geophysicae 18. 2000, 1340-1348.

27. MacGorman D. R., et al. Lightning rates relative to tornadic storm evolution on 22, May 1981. J. Atmos. Sci., 46. 1989, 221-250.

28. MacGorman D. R., Rust W. D. The electrical nature of storms. Oxford University Press. 1998, 422 pages.

29. Mackerras D. Prediction of Lightning Incidence and Effects in Electrical Systems. Electr. Eng. Trans. Inst. Aust., EE-14. 1978, p. 73-77.

30. Brian I. M. Global Lightning Parameterization from CMIP5 Climate Model Output. Journal of atmospheric and oceanic technology, Volume 32. 2015, 434-452.

31. McFarlane N. A., Boer G. J., Blanchet J. P., Lazare M. The Canadian Climate Centre Second Generation General Circulation Model and its Equilibrium Climate. J. Climate, 5. 1992, 1013-1044. 
32. McFarlane. Description of the Canadian regional climate model. Water, Air and Soil Pol., 82. 1995, 477-482.

33. McNicol, D. K., Mallory, M. L., Sechley, J. Acid rain and wildlife. An annotated bibliography of Canadian Wildlife Service (Ontario region): LRTAP program publications: (1980-1997), Technical Report Series / Canadian Wildlife Service; no. 305. $1998,70 \mathrm{p}$.

34. Mickey R. M., Dunn O. J., Clark V. A. Applied statistics: analysis of variance and regression. 3rd ed., Edition Hoboken, N.J. : Wiley-Interscience. 2004, 448 pages.

35. Norville K., Baker M., Latham J. A numerical study of thunderstorm electrification: Model development and case study. J. Geophy. Res. 96. 1991, 7463-7481.

36. Orville R. E., Huffines G. R. Lightning ground flash measurements over contiguous United States: 1995-1997. Mon. Weather Rev., 127. 1999, 2693-2703.

37. Rabinovitz F. et al. A Variable-Resolution Stretched-Grid General Circulation Model: Regional Climate Simulation, Monthly Weather Review Volume: 129 Issue: 3. 2001, Pages: 453- 469.

38. Radojevic M. Chemistry of Forest Fires and Regional Haze with Emphasis on Southeast Asia. Pure Appl. Geophys., 160. 2003, 157-187.

39. Reader M. C., Boer G. J. The modification of greenhouse gas warming by the direct effect of sulfate aerosols. Climate Dynamics, 14. 1998, 593-607.

40. Reid J. S., et al. Relationships between cloud droplet effective radius, liquid water content, and droplet concentation for warm clouds in Brazil embedded in biomass smoke. Journ. Of Geophy. Research, Vol. 104, NO. D6. 1999, 6145-6153. 
41. Ressources naturelles Canada. L'état des forêts au Canada, 1999-2000. Service canadien des forêts. 2000, 122 pages.

42. Devendraa S., R.P. Singh, Sarvan Kumar, T. Dharmaraj, Abhay K. Singh, Ashok K. Singh, M.N. Patil, Shubha Singh. Lightning and middle atmospheric discharges in the atmosphere. Journal of Atmospheric and Solar-Terrestrial Physics. 2015, 78-101.

43. Sanford, W. Applied linear regression. $3^{\text {rd }}$ ed. Edition Hoboken, N.J.: John Wiley and Sons. 2005, 310 pages.

44. Sartor, J. D. A laboratory investigation of collision efficiencies, coalescences and electrical charging of simulated cloud droplets. J. Meteor., 11. 1954, pp. 91-103.

45. Sartor, J. D. The role of particle interactions in the distribution of electricity in thunderstorms. J. Atmos. Sci., 24. 1967, 601-615.

46. Sexton D. M. H., et al. Detection of anthropogenic climate change using an atmospheric GCM. Climate Dynamics. 17. 2001, 669-685.

47. Solomon R., Baker M. A one-dimensional lightning parameterization. Jour. Geophy. Res. 101. 1996, 14,983-14,990.

48. Solomon R., Baker M. Lightning flash rate and type in convective storms. Jour. Geophy. Res. 103. 1998, 14,041-14,057.

49. Solomon R., et al. Relating cloud microphysical properties and lightning model analysis of an extreme hailstorm. Proceeding of the 5rd EGS Plinius Conference held at Ajaccio, Corsica, France. 2003. 
50. Soriano L. J. R., De Pablo F., Garcia Diez E. L. Meteorological and geo-orographical relationships with lightning activity in Castilla-Leon (Spain). Meteorol. Appl. 8. 2001, 169-175.

51. Stratton S. A. Report on aspects of variability in high-resolution versions of HadAM3, Hadley Centre technical note 53. 2004.

52. Spacek L., et al. The NARCM Aerosol Model Applied to Eastern North America LITE Shuttle Measurement Period, J. Geophys. 1999.

53. Therien J., Gadian A. Influence of topography and urban heat island effects of the outbreak of convective storms under unstable meteorological conditions: Met. Appl.4. 1997, 139-149.

54. Therien, D. Le modèle de circulation générale atmosphérique canadien en version colonne : FIZ-C. Université du Québec à Montréal. 1993, 123 pp.

55. Thielen J., McIllveen J. F. R. Topographical influence on severe convective storms. In Conf. Proceedings on the 2nd Int. Symp. Hydr. Applic. Of Weather Radar. University of Hannover. 1996.

56. Thielen J., Gadian A. Influence of topography and urban heat island effects on the outbreak of convective storms under unstable meteorological conditions: Meteorol. Appl. 4. 1997, 139-149.

57. Tokahashi, T. Warm cloud electricity in a shallow axisymmetric cloud model. J. Atmos. Sci., 36. 1979, 2236-2258.

58. Kochtubajda B., et al. Lightning and Fires in the Northwest Territories and Responses to Future Change. Arctic, Vol. 59, NO. 2. 2006, 211-221. 
59. Lang T. J., Rutledge S. A Relationship between convective Storm Kinetics, Precipitation, and Lightning. Month. Weat. Re., 130. 2002, 2492-2506.

60. Lavoué, D., C. Liousse, H. Cachier, B.J. Stocks, J.G. Goldammer. Modeling of carbonaceous particles emitted by boreal and temperate wildfires at northern latitudes. Journal of Geophysical Research, 105, D22. 2000, 26,871-26,890.

61. Lavoué, D. Transport vers la région arctique de l'aérosol carbone émis par les feux de biomasse des régions boréales et tempérées. Thèse de doctorat, Laboratoire des sciences du climat et de l'environnement, Université Paris 7. 2000.

62. Leduc, R. Acid precipitation in Québec: état de la situation. Québec, Ministère de l'environnement et de la faune. 1996, 49 pages.

63. Lowe, J. A., Gregory, J. M., Flather, R. A. Changes in the occurrence of storm surges around the United Kingdom under a future climate scenario using a dynamic storm surge model driven by the Hadley Centre climate models. Climate Dynamics, 18. 2001, $179-188$.

64. Papadopol C. S. Impacts of climate warming on forests in Ontario: options for adaptation and mitigation. The Forestry Chronicle, 76 (1).2000, 139-149.

65. Penner J. E., Chan S. J., Walton J. J. The role of biomass burning in the budget and cycle of carbonaceous soot aerosols and their climate impact. Climate Biomass burning, J. Levine, Ed., MIT Press. 1991, 387-393.

66. Penner J. E., Chuang C. C., Grant K. Climate forcing by carbonaceous and sulfate aerosols. Climate Dynamics, 14. 1998, 839-851. 
67. Petersen W. A., Rutledge S. A. On the relationship between cloud-to-ground lightning and convective rainfall. J. Geophys. Res., 103. 1998, 14025-14040.

68. Price C., Rind D. A simple Lightning parameterization for calculating global lightning distributions. J. Geophys. Res. 97. 1992, 9919-9933.

69. Uman M. A. The Lightning Discharge. Academic Press, San Diego, CA, International geophysics series, V. 39 xii. 1987.

70. Verseghy D. L. CLASS - A Canadian Land Surface Scheme for GCMS-I, Soil Model. International Journal of Climatology, vol. 11. 1991, 111-133.

71. Verseghy D. L., McFarlane N. A., Lazare M. CLASS - A Canadian Land Surface Scheme for GCMS-II, Vegetation Model and Complet Runs. International Journal of Climatology, vol. 13. 1993, 347-370.

72. Weber M. G., Flannigan M. D. Canadian boreal forest ecosystem structure and function in a changing climate: impact on fire regimes. Environ. Res., 5 (3 and 4). 1997, 145166.

73. Weiss D., Shotyk W., Kempf O. Review articles: Archives of Atmospheric Lead Pollution. Naturwissenschaften, 86. 1999, 262-275.

74. Wierzchowski J. Heathcott M., Flannigan M.D. Lightning and lightning fire, central cordillera, Canada. International Journal of Wildland Fire, vol. 11, n. 1. 2002, 41-51.

75. Wilson C. T. R. Some thundercloud problems. J. Franklin Inst., 208. 1929, 1-12.

76. Williams E. R. Large-scale charge separation in thunderstorm. J. Geophy. Res., 90. $1985,6013-6025$.

77. Williams E. R., Renno N. An analysis of the conditional instability of the tropical atmosphere. Mont. Weather Res., 121. 1993, 21-36. 
78. Xiushu Q., Toumi R., Yunjun Z. Lightning activity on the central Tibetan Plateau and its response to convective available potential energy. Chinese science Bulletin, vol. 48 , N³. 2003, 296- 299.

79. Zhou Y., Qie X., Soula S. A study of the relationship between cloud-to-ground lightning and precipitation in the convective weather system in China. European Geophysical Society, 20. 2002, 107-113. 